Doi: 10.35414 /akufemubid.459904

\author{
Araştırma Makalesi / Research Article
}

\title{
Farklı Ortam Sıcaklıklarının Kompozit Restoratif Malzemelerin Mekanik Ve Tribolojik Davranışları Üzerindeki Etkisinin İncelenmesi
}

\author{
Efe Çetin YILMAZ \\ Kilis 7 Aralık Üniversitesi, Mühendislik Fakültesi, Makine Mühendisliği Bölümü, Kilis. \\ e-posta: efecetinyilmaz@msn.com \\ https://orcid.org/0000-0002-6212-7483 \\ Geliş Tarihi: 14.09.2018 ; Kabul Tarihi: 13.02.2019
}

Öz

Bu çalışmanın amacı, farklı ortam sıcaklıklarının üç farklı kompozit restoratif malzemesinin mekanik ve tribolojik davranışları üzerindeki etkisinin incelenmesidir. Bu çalışmada, kompozit malzemelerin sertlik, yüzey pürüzlülüğü ve direkt-temas aşınma davranışları üç farklı ortam sıcaklığındaki çiğneme test

Anahtar kelimeler

Kompozit malzeme;

Aşınma; Çiğneme

Simülasyonu; Hacim kaybı deneylerinde $\left(5^{\circ} \mathrm{C}, 37^{\circ} \mathrm{C}\right.$ ve $\left.55^{\circ} \mathrm{C}\right)$ incelenmiştir. Çiğneme test deneyleri saf su içerisinde üç farklı ortam sıcaklığında $50 \mathrm{~N}$ üst çene ısırma kuvveti, $0.7 \mathrm{~mm}$ alt çene yanal hareketi, 240.000 mekanik yükleme, $1.6 \mathrm{~Hz}$ çiğneme periyodu ve $6 \mathrm{~mm}$ çapında $\mathrm{Al}_{2} \mathrm{O}_{3}$ karşı malzeme olarak uygulanmıştır. Kompozit malzemelerin her çiğneme test grubu sonrasında sertlik, yüzey pürüzlülüğü ve ortalama aşınma hacim kaybı değerleri belirlenmiştir. Ayrıca, her test grubundan rastgele numuneler seçilerek 3D profilometre ve taramalı elektron mikroskobu görüntüleri alınarak aşınma yüzeyi analizleri yapılmıştır. Bu çalışma sonucunda, çiğneme ortam sıcaklığının artması ile test edilen tüm kompozit malzemelerin sertlik değerlerinde azalmalar gözlemlenmiştir. Kompozit malzemenin monomer yapısında içerdiği organik matris yapısı çiğneme ortam sıcaklığının artması ile kompozit malzemenin daha belirgin yüzey pürüzlülüğüne sahip olmasına katkı sağlamıştır.

\section{Investigation Effect of Different Ambient Temperature on Mechanical and Tribological Behaviour of Composite Restorative Materials}

\footnotetext{
Abstract

The purpose in this study, investigation effect of different ambient temperature on mechanical and tribological behaviour of three different composite restorative materials. In this study, hardness, surface roughness and direct-contact wear behaviors of composite materials were investigated in chewing test experiments $\left(5^{\circ} \mathrm{C}, 37^{\circ} \mathrm{C}\right.$ and $\left.55^{\circ} \mathrm{C}\right)$ at three different ambient temperatures. Chewing test experiments were performed in distill water at three different ambient temperatures as $50 \mathrm{~N}$ bite force

Keywords

Composite material; Wear; Chewing Simulation; Volume Loss bite force of upper jaw, $0.7 \mathrm{~mm}$ lateral movement of lower jaw, 240,000 mechanical loading, $1.6 \mathrm{~Hz}$ chewing period and $6 \mathrm{~mm}$ diameter $\mathrm{Al}_{2} \mathrm{O}_{3}$ antagonist material. The hardness, surface roughness and mean wear volume loss values of composite materials were determined after each chewing test group. In addition to, a random specimen was selected from each test group with 3D profilometer and Scanning Electron Microscope (SEM) images were taken for analysis of wear tracks. As a result of this study, it has been observed that the decrease hardness values of all composite materials of tested with increasing chewing ambient temperature. The organic matrix structure of the monomer of the composite material contributes to the increased surface temperature of the chewing material and the more significant surface roughness of the composite material.
} 


\section{Giriş}

Son yıllarda, kompozit restoratif malzemelerin üstün mekanik ve estetik özelliklere sahip olmasından dolayı klinik çalışmalarda giderek artan bir kullanımı görülmektedir (Osiewicz et al. 2015). Ağız içi tribolojik süreçte kompozit malzemenin sahip olduğu mekanik ve estetik özellikleri genel olarak ağız içi ortam sıcaklığı, çiğneme sırasında oluşan yük dağılımlarına bağlıdır. Literatürde, insan çiğneme sırasında ağız içi tribolojik süreçte $1{ }^{\circ} \mathrm{C}$ ile $50{ }^{\circ} \mathrm{C}$ sıcaklık değişiminin oluştuğu rapor edilmiştir (Ramalho, de Carvalho, and Antunes 2013; Musanje and Darvell 2004). Canlı doku (in vivo) çalışmalarda, sıcak bir yiyeceğin ağız ortamında alınmasında alt çene ön ısırma dişlerinde ortalama $46.4{ }^{\circ} \mathrm{C}$ ve üst çene ısırma dişlerinde $41.6{ }^{\circ} \mathrm{C}$ olduğu rapor edilmiştir (Feuerstein et al. 2008). İnsan ağız içi tribolojik süreci laboratuvar ortamında testlerinin gerçekleştirilmesinde bu sıcaklık aralıklarının referans alınması önemlidir.

Ağız içi tribolojik sürecin sürekli ve karmaşık yapısı kompozit malzemelerin sahip olduğu mekanik ve estetik özellikleri etkilemektedir. Literatürde, klinik çalışmalarda tedavi sürecinde kompozit malzemelerin yaklaşık olarak \% 12 ile \% 19 arasında kırılma hasarına uğradıkları rapor edilmiştir (Brunthaler et al. 2003). Ağız içi tribolojik süreçte meydana gelen bu hasarın yaklaşık \% 6.1 kompozit malzemenin zayıf aşınma direncinden kaynaklandığı rapor edilmiştir (van Dijken 2000). Ağız içi tribolojik süreçte genel olarak dört aşınma mekanizmasının meydana geldiği varsayılabilir. $\mathrm{Bu}$ aşınma mekanizmalarını direkt temas aşınması (two-body wear), aşındırıcı ortam aşınması (three-body wear), korozyonlu aşınma (corrosive wear) ve yorulmalı aşınma (fatigue wear) olarak isimlendirmek mümkündür. Ağız içi tribolojik süreçte çiğneme sırasında genel olarak, kompozit_malzemenin direkt diş ile temasıyla geçekleşen direkt temas aşınma mekanizması ve diş ile kompozit malzeme arasına üçüncü aşındırıcı bir ortamın dahil olması (genelde yiyecek parçacıkları) aşındırıcı ortam aşınma mekanizmaları meydana gelmektedir. Insan çiğneme hareketi sırasında bu aşınma mekanizmaları tek başına veya bütünleşik olarak meydana gelebilmektedir (Mair et al. 1996).

Literatürde birçok çiğneme simülatör cihazının direkt-temas aşınma ve aşındırıcı ortam aşınma mekanizmalarını oluşturarak ağız içi tribolojisini simüle ettiği rapor edilmiştir (Wimmer et al. 2016; Lazaridou et al. 2015; Hahnel et al. 2011). Çiğneme simülatörlerinde uygulanan parametreler kompozit malzemenin aşınma davranışı üzerinde önemli bir etkiye sahiptir. Bu yüzden, laboratuvar ortam deneylerinin geçerliliği için çiğneme simülatör cihazlarının uyguladığı parametreler ağız içi tribolojide oluşan parametrelere benzer olmak zorundadır. Literatürde, ağız içi tribolojide ısırma kuvvetinin $20 \mathrm{~N}$ ile $120 \mathrm{~N}$ arasında değişiklik gösterdiği rapor edilmiştir (Heintze 2006). Bu çalışma kapsamında seçilen $50 \mathrm{~N}$ ısırma kuvveti (dikey yükleme) miktarı çiğneme sırasında ortalama bir gerilme olarak düşünülmüştür. Literatürde birçok çalışmada da ortalama ısırma kuvveti yaklaşık $50 \mathrm{~N}$ olarak seçilmiştir (Lazaridou et al. 2015; Koottathape et al. 2012; Wimmer et al. 2016). Literatürde, laboratuvar çalışmalarında ağız içi tribolojide çiğneme sayısının 50.000 ile 1.200 .000 arasında değişkenlik gösterdiği rapor edilmiş ve bir insanın günlük ortalama 300 ile 700 çiğneme hareketi yaptığı bildirilmiştir (Lazaridou et al. 2015). Bu çalışmada seçilen 240.000 çiğneme döngü sayısı tedavi sürecinde yaklaşık olarak 1 ile 2 yıl klinik çalışmalara denk gelmektedir.

Kompozit malzemeler tedavi sürecinde ağız içerisine yerleştirildiklerinde çiğneme hareketi sırasında sürekli olarak termal değişime maruz kalmaktadırlar (Ramalho, de Carvalho, and Antunes 2013). Ağız içi tribolojik süreçte gerçekleşen bu termal değişim döngüsü kompozit malzemelerin mekanik ve 
tribolojik özeliklerini önemli ölçüde etkilemektedir (Ramalho, de Carvalho, and Antunes 2013). Bu yüzden, bu çalışmanın amacı, ağız içi tribolojik sürecin laboratuvar ortamında modellenerek, farklı ortam sıcaklıklarının üç faklı kompozit restoratif malzemenin mekanik ve tribolojik davranışları üzerindeki etkisinin incelenmesidir.

\section{Materyal ve Metot}

$\mathrm{Bu}$ çalışmada test edilen kompozit malzemelerin kimyasal içeriği tablo 1 de gösterilmiştir (bilgiler üretici firma tarafından sağlanmıştır). Kompozit malzemelerden her deney grubu için ( $6 \mathrm{~mm}$ yarıçap $\mathrm{X} 2 \mathrm{~mm}$ boy) silindirik biçimde numuneler üretilmiştir. Çiğneme test deneylerinde karşı malzeme olarak $6 \mathrm{~mm}$ çapında $\mathrm{Al}_{2} \mathrm{O}_{3}$ bilye toplar kullanılmıştır. Şekil 1 de üretimi tamamlanmış ve akrilik rezin içerisine gömülmüş kompozit test numunesi ve karşı malzeme (antagonist) görülmektedir. Çiğneme test deneyleri eş zamanlı olarak 2 eksende hareket kabiliyetine sahip termal yorulma ve çiğneme simülatör cihazı kullanılarak gerçekleştirilmiştir. Şekil 2 de çiğneme hareketinin sistematiği gösterilmiştir.

Çizelge 1. Kompozit malzemelerin kimyasal içeriğinin gösterimi

\begin{tabular}{|c|c|c|}
\hline \multicolumn{3}{|l|}{ Kompozit Malzeme / Kod } \\
\hline Üretici / Doldurucu Tipi & Monomer & Doldurucu Yapısı - Doldurucu Ağırlığı \% / Hacmi \% \\
\hline \multicolumn{3}{|l|}{ Voco Grandio /Grandio } \\
\hline Voco/ Nanohybrid & Bis-GMA TEGDMA Bis-EMA & $\mathrm{ZrO}_{2}, \mathrm{SiO}_{2}, \mathrm{SiO}_{2}, \mathrm{Ba}-\mathrm{Al}-\mathrm{B}-\mathrm{SiGlass} / 0,1-2,5 \mu \mathrm{m}-$ \\
\hline \multicolumn{3}{|l|}{ Filtek Supreme XT/ FIL } \\
\hline 3M ESPE,St. Paul, MN,USA Nanofilled & Bis-GMA, UDMA, BisEMA, TEGDMA & Nanosilica Zirconia/silica Nanoclusters 5-20nm - 78 / 60 \\
\hline \multicolumn{3}{|l|}{ Filtek Z250 /Z250 } \\
\hline 3M ESPE, St. Paul, MN, USA/Micro-hybrid & Bis-GMA, Bis-EMA,UDMA & $\mathrm{SiO}_{2}, \mathrm{ZrO}_{2}(0.01-3.5 \mathrm{~mm}$, average $0.6 \mathrm{~mm})$ \\
\hline
\end{tabular}

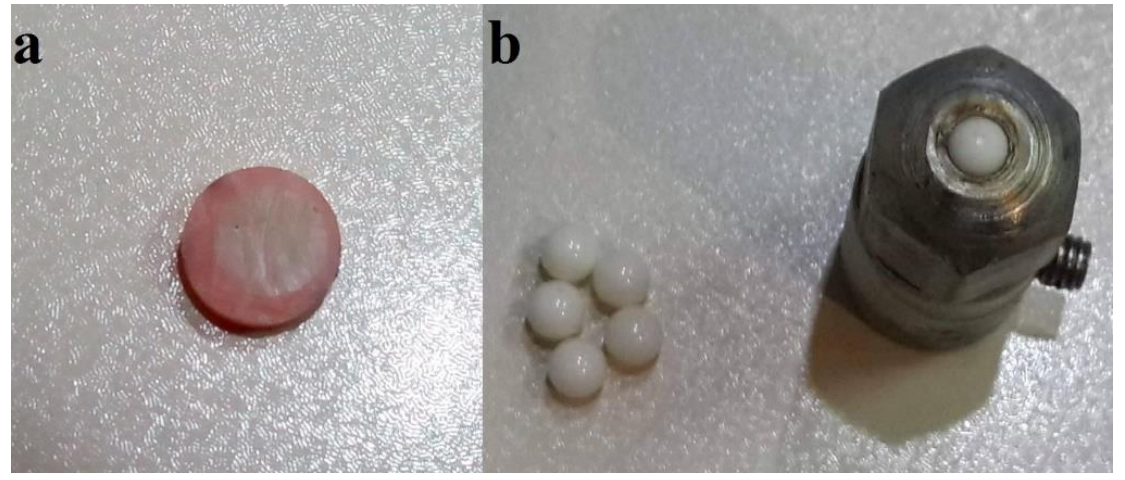

Şekil 1. Test numunesi ve karşı malzeme örneğinin gösterimi (a: test numunesi b: karşı malzeme) 


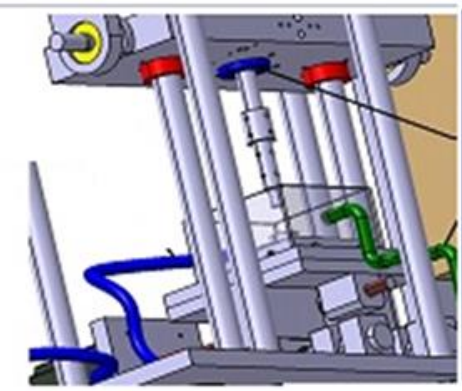

a)

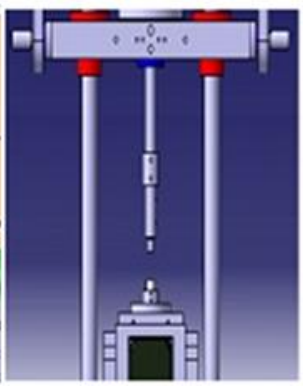

b)

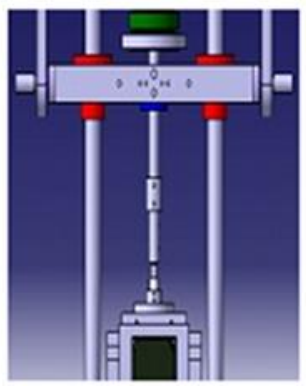

)

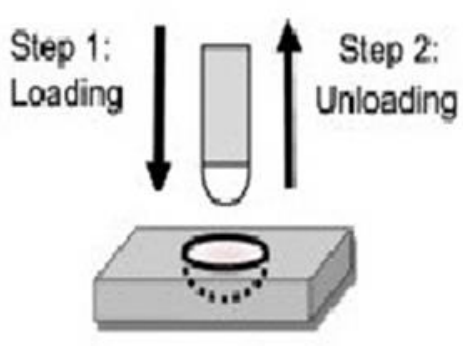

c)

Şekil 2. Eş zamanlı 2 eksende hareket kabiliyetine sahip çiğneme simülatör sistematiğinin gösterimi

Çiğneme simülasyon cihazı tüm testler boyunca saf su çözeltisi içerisinde $5{ }^{\circ} \mathrm{C}, 37^{\circ} \mathrm{C}$ ve $55^{\circ} \mathrm{C}$ ortam sıcaklıklarında $50 \mathrm{~N}$ üst çene ısırma kuvveti, $0.7 \mathrm{~mm}$ alt çene yanal hareketi, 240.000 mekanik yükleme, $1.6 \mathrm{~Hz}$ çiğneme periyodu yapacak şekilde programlanmıştır. Çiğneme test deneyleri sonrasında üç boyutlu dokunmadan taramalı (3Dnon-contact) profilometre kullanılarak yüzey pürüzlülük ve aşınma hacim kayıpları belirlenmiştir. Ayrıca test deneyleri sonrasında kompozit malzemelerin sertlik değerleri Vicker's sertlik yöntemi ile belirlenmiştir. Ortam sıcaklığı $55{ }^{\circ} \mathrm{C}$ seçilen test grubunda test edilen kompozit malzemelerin mikro yapısını incelemek amacıyla taramalı elektron mikroskobu (SEM) kullanılarak aşınma yüzey görüntüleri elde edilmiştir.

\section{Bulgular ve Tartışma}

Bu çalışmada test edilen kompozit malzemelerin 5 ${ }^{\circ} \mathrm{C}, 37^{\circ} \mathrm{C}$ ve $55^{\circ} \mathrm{C}$ ortam sıcaklıklarında gerçekleşen çiğneme test deneyleri sonrasında edilen sertlik, yüzey pürüzlülüğü ve ortalama aşınma hacim kaybı tablo 2 de gösterilmiştir. Tablo 2 incelediğinde, test edilen tüm kompozit malzemelerin setlik değerleri sıcaklık artışı ile bir azalış eğilimi göstermiştir. Bu durum çiğneme testi sırasında ortam sıcaklı̆̆ı ile su emilim difüzyonun artmasının kompozit malzeme monomer yapısında bozulmayı hızlandırıcı bir etki oluşturduğu olarak yorumlanmıştır. Literatürde de ortam sıcaklığının artması ile kompozit malzemenin sahip olduğu sertlik değerlerinde azalmalar olduğu rapor edilmiştir (Ramalho, de Carvalho, and Antunes 2013). Çiğneme testi sonrasında ortam sıcaklıklarında bu çalışmada test edilen tüm kompozit malzemelerin yüzey pürüzlülük değerleri artış göstermiştir. Ancak kompozit malzemenin monomer yapısında organik matris yapısı (TEGDMA, TEGMA gibi) içermesi tüm ortam sıcaklıklarında kompozit malzemenin daha yüksek yüzey pürüzlülük değerlerine sahip olmasına katkı sağlamıştır. Bu durum monomer yapısında bulunan bu yapının hidrolotik bozunma mekanizmasını artıcı bir etki oluşturması ile açıklanabilir. Literatürdeki çalışmalarda, kompozit malzemenin monomer yapısında organik matris yapısı içermesinin daha yüksek yüzey pürüzlük değerleri oluşmasında önemli bir etken olduğu rapor edilmiştir (Hahnel et al. 2010; Yilmaz and Sadeler 2017).

Şekil 3 çiğneme test deney sonrası kompozit malzeme yüzeyinde oluşan aşınma bölgesi 3 boyutlu örneğini göstermektedir. Şekil 3 incelendiğinde, kompozit malzemede çiğneme testi sırasında ısırma kuvvetinin meydana geldiği bölgede en fazla aşınma derinliğinin oluştuğu görülecektir. Ayrıca aşındırıcı karşı malzemenin silindirik geometride seçilmesi kompozit malzemenin homojen bir aşınma bölgesine sahip olmasına katkı sağladığını söylemek mümkündür. Laboratuvar ortamında uygulanan çiğneme test deneylerinde karşı aşındırıcı malzemenin geometrisi, boyutu ve mekanik özellikleri kompozit malzemenin aşınma davranışı üzerinde büyük bir etkiye sahiptir. Bu nedenle bu çalışmada her çiğneme test deneyi için $6 \mathrm{~mm}$ çapında dairesel $\mathrm{Al}_{2} \mathrm{O}_{3}$ bilyelerin kullanımı tercih edilmiştir. Literatürde de, $6 \mathrm{~mm}$ çapındaki dairesel bilye topların canlı doku üzerinde çiğneme hareketi sırasında aşındırıcı karşı malzemeyi simüle ettiği 
rapor edilmiştir (Ghazal and Kern 2009; Lazaridou et al. 2015). Şekil 4 de bu çalışmada test edilen kompozit malzemelerin $50{ }^{\circ} \mathrm{C}$ ortam sıcaklığında gerçekleşen çiğneme test sonrasındaki aşınma çizgilerinin oluştuğu bölgeleri göstermektedir. Şekil 5 de bu çalışmada test edilen kompozit malzemelerin $55{ }^{\circ} \mathrm{C}$ ortam sıcaklığında gerçekleşen çiğneme test deneylerinde oluşan mikro yapılarını göstermektedir. Kompozit malzemelerin mikro yapı görüntüsü incelendiğinde genel olarak, çiğneme hareketi sırasında alt çene hareketi ile malzeme aşınma yüzeyinden parçacıkların taşındığı görülecektir.

Çizelge 2. Kompozit malzemelerin çiğneme testleri sonrasında mekanik ve tribolojik özelliklerinin gösterimi (A: Sertlik, B: Yüzey Pürüzlülüğü C:Ortalama aşınma hacim kaybı)

\begin{tabular}{|c|c|c|c|c|c|c|c|c|c|}
\hline \multirow[b]{3}{*}{ Grandio } & \multicolumn{3}{|c|}{$5^{\circ} \mathrm{C}$ ortam sıcaklığı } & \multicolumn{3}{|c|}{$37^{\circ} \mathrm{C}$ ortam sıcaklığı } & \multicolumn{3}{|c|}{$55^{\circ} \mathrm{C}$ ortam sıcaklığı } \\
\hline & \multicolumn{3}{|c|}{$\mathrm{HV}(\mathbf{A}) \mu \mathrm{m}(\mathrm{B}) \mathrm{mm}^{\wedge} 3(\mathrm{C})$} & \multicolumn{3}{|c|}{$\mathrm{HV}(\mathrm{A}) \mu \mathrm{m}(\mathrm{B}) \mathrm{mm}^{\wedge} \mathrm{3}(\mathrm{C})$} & \multicolumn{3}{|c|}{$\mathrm{HV}(\mathrm{A}) \mu \mathrm{m}(\mathrm{B}) \mathrm{mm}^{\wedge} 3(\mathrm{C})$} \\
\hline & 108.3 & 0.16 & 2.86 & 92.1 & 0.19 & 3.89 & 81.6 & 0.26 & 3.09 \\
\hline Z250 & 91.5 & 0.09 & 2.69 & 74.7 & 0.11 & 2.64 & 69.8 & 0.15 & 2.78 \\
\hline Supreme & 54.8 & 0.12 & 3.17 & 47.1 & 0.16 & 3.15 & 41.2 & 0.22 & 3.52 \\
\hline
\end{tabular}

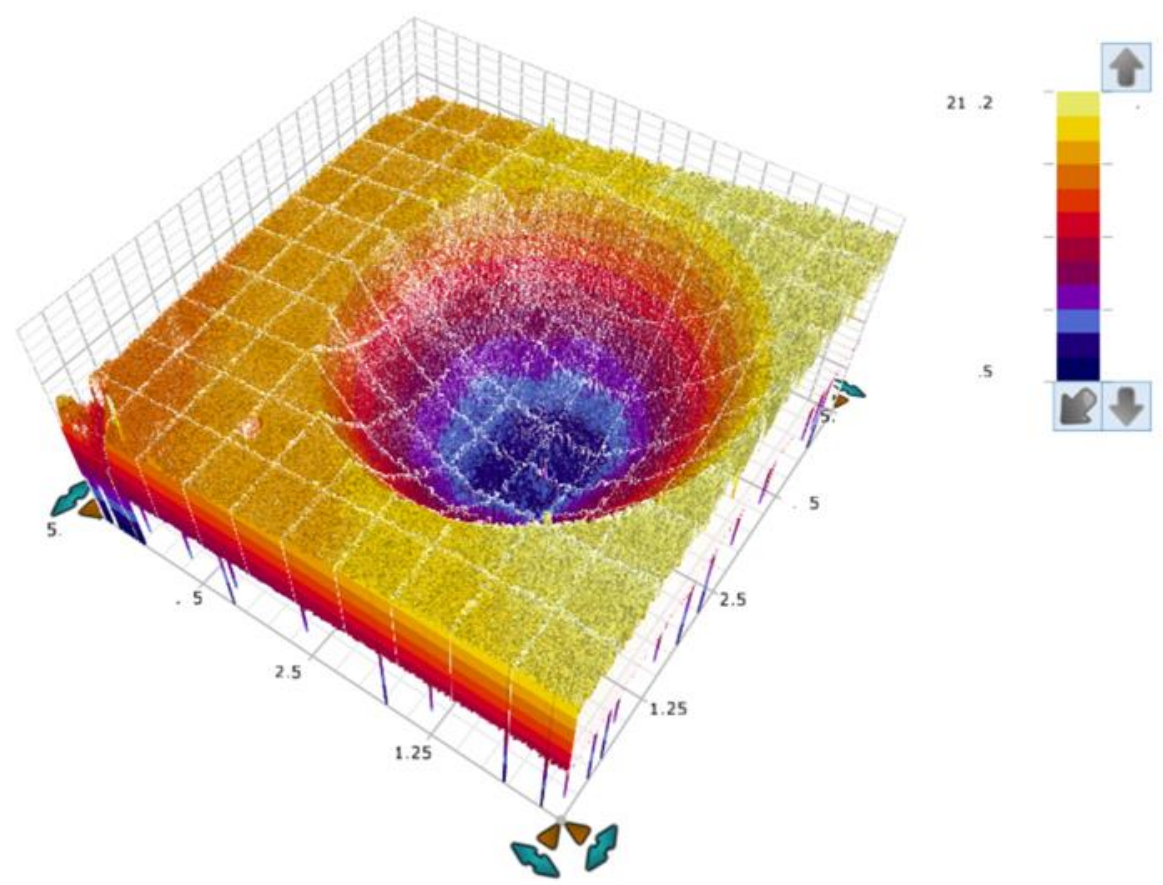

Şekil 3. Çiğneme test deneyi sonrasın kompozit malzeme yüzeyinde oluşan aşınma bölgesinin 3 boyutlu gösterimi 


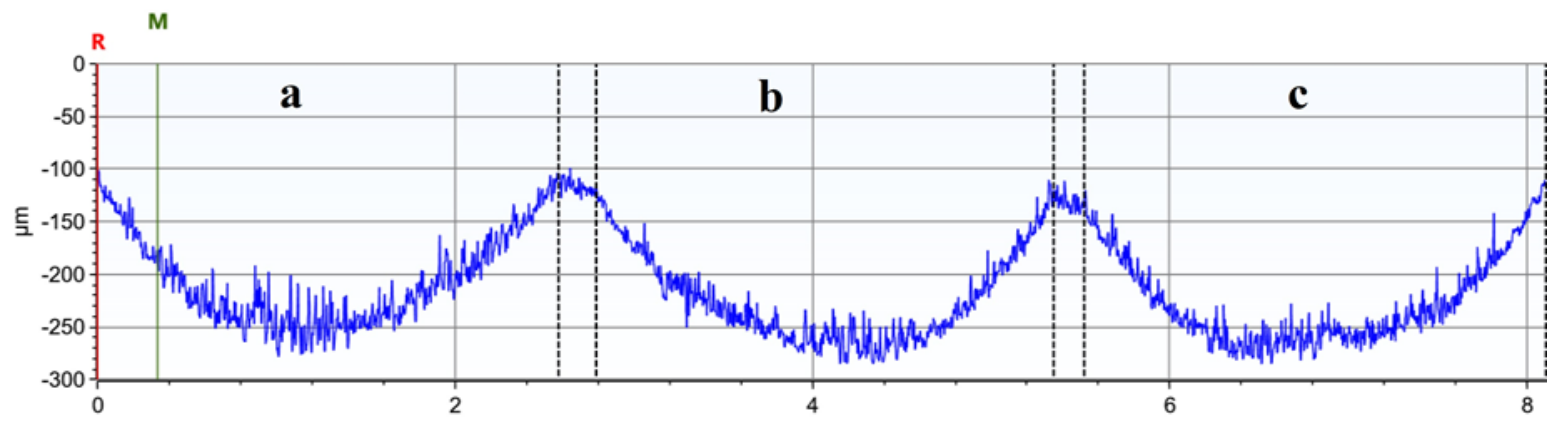

Şekil 4. Kompozit malzemelerin $55{ }^{\circ} \mathrm{C}$ ortam sıcaklığında gerçekleşen çiğneme test deneylerinde oluşan aşınma bölgelerinin 2 boyutlu gösterimi (a: Grandio, b: Z250 c:Supreme)

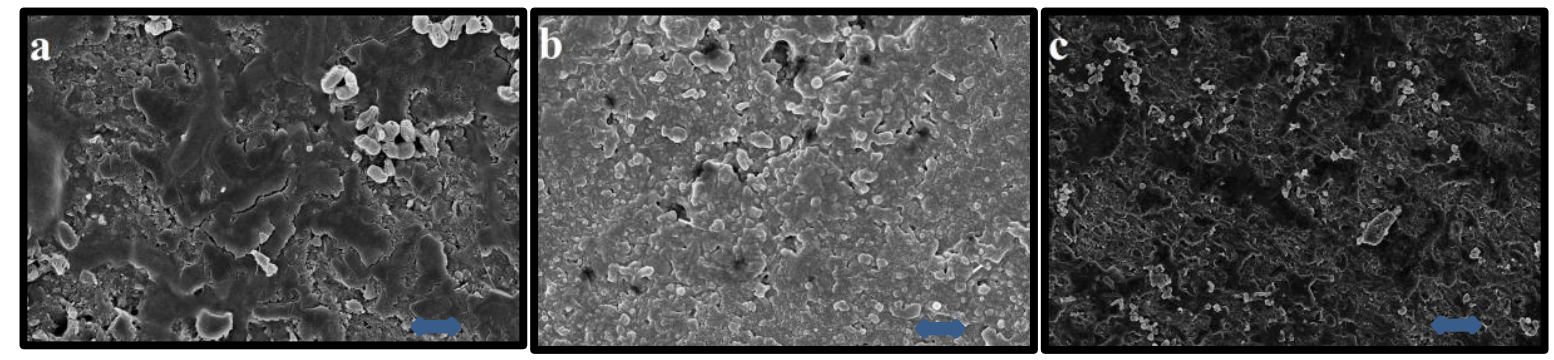

Şekil 5. Kompozit malzemelerin $50^{\circ} \mathrm{C}$ ortam sıcaklığında gerçekleşen çiğneme test deneylerinde oluşan mikro yapılarının gösterimi ( 5 kV $2 \mu \mathrm{m}$ a: Z250, b: Grandio c:Supreme)

Malzeme mühendisliği açısından kompozit restoratif malzemesinde bulunan parçacık boyutundaki gelişmeler, iki farklı parçacık içeren bir kimyasal bileşim üretmiştir. $\mathrm{Bu}$ kompozit malzemeler, mikro veya nano-parçacık büyüklüğüne ve içeriğine bağıı olarak mikro veya nano hibrit reçine kompozitleri olarak adlandırılır (Souza et al. 2016). Kompozit restoratif malzemeleri ticari olarak, mikro ve nano yapılı türevlerini ayırt etmek çoğu zaman zordur çünkü bu kompozit malzemeler hem mikro yapılıdırlar hem de mekanik davranış olarak birbirlerine çok benzer yapıdadırlar (Souza et al. 2016).

Literatürde, ağız içi tribolojide kompozit restoratif malzemelerde aşınma mekanizmasının 2 aşamada meydana geldiği rapor edilmiştir (Obrien and Yee 1980; Yilmaz and Sadeler 2018). ilk olarak, kompozit malzemede organik matris yapısının aşınması ile inorganik parçacıklar monomer yapısından uzaklaşır ve aşınma yüzeyinde pürüzlü bir yapı meydana gelir
(Jorgensen 1980). Daha sonra ayrılan bu inorganik parçacıklar kompozit malzeme yüzeyinde aşındırıcı bir etki oluştururlar. Bu parçacıklar üçüncü bir ortam gibi hareket ederek kompozit malzemenin aşınma davranışını etkileyebilirler. Bu yüzden, bu çalışmada bu üçüncü ortam parçacıklarının etkisini ortadan kaldırabilmek için ortam sıcaklığındaki su kompozit malzeme yüzeyine 1 saniye aralıklarla püskürtülmüştür. Böylelikle çalışmada bahsedilen direkt-temas aşınması (two-body wear) mekanizması ağız içi tribolojiye uygun olarak simüle edilmiştir.

Bu deneysel çalışma sonrasında test edilen tüm kompozit farklı ortam sıcaklıklarında farklı direkt temas aşınma davranışı göstermişlerdir. Bu durum kompozit malzemelerin içerdiği doldurucu yapısı ve monomer yapısı ile ilgilidir. Şekil 4 incelendiğinde 55 ${ }^{\circ} \mathrm{C}$ ortam sıcaklığında gerçekleşen çiğneme test deneylerinde Grandio kompozit malzemenin daha pürüzlü bir aşınma bölgesi gösterdiği görülecektir 
(Şekil 4 a). Bu durumun oluşmasında çiğneme hareketi sırasında ısırma kuvvetinin oluştuğu (dikey yükleme) sırasında Grandio kompozit malzemesinin içerdiği Ba-Al-B-Si cam parçacıklarının monomer yapısından daha kolay ayrılarak kompozit malzemenin daha pürüzlü bir aşınma bölgesine sahip olmasına katkı sağladığını söylemek mümkündür. Literatürde aşınma test deneylerinde, monomer yapısında cam parçacıkları içeren nanohibrit dolduruculu GrandiosO Flow kompozit malzemesinin nano-dolduruculu Supreme kompozit malzemesine göre belirgin bir şekilde daha fazla yüzey pürüzlülüğü davranışı gösterdiği rapor edilmiştir (Lazaridou et al. 2015).

\section{Değerlendime}

Bu deneysel çalışma sınırları kapsamında elde edilen veriler ile aşağıdaki değerlendirmeler yapılmıştır.

- Çiğneme test deneylerinde ortam sıcaklığının artması ile bu çalışmada test edilen tüm kompozit malzemelerin mekanik ve tribolojik davranışları etkilenmiştir.

- Kompozit malzemenin monomer yapısında içerdiği organik matris yapısı (TEGDMA,TEGMA gibi) kompozit malzemenin tüm çiğneme test deneyleri sonrasında daha yüksek yüzey pürüzlülük değerine sahip olmasına neden olmuştur. Kompozit malzemede yüzey pürüzlülüğün artması malzemenin aşınma davranışı olumsuz yönde etkileyerek çiğneme test deneyleri sonrasında daha fazla hacim kaybına uğramasına neden olmuştur.

- Grandio kompozit malzemesinin içerdiği BaAl-B-Si cam parçacıkları kompozit malzemenin tüm ortam sıcaklıklarında daha yüksek sertlik değerinde olmasına katkı sağlamıştır. Ancak bu camsı doldurucu yapının yüksek sıcaklıkta malzeme aşınma bölgesinden daha kolay ayrılarak kompozit malzemenin daha pürüzlü bir aşınma yüzeyine sahip olmasına katkı sağlamıştır.
- Bu çalışmada test edilen tüm kompozit malzemelerde en düşük hacim kaybı vücut sıcaklığında meydana gelmiştir. Elde edilen bu sonucun klinik çalışmalarda ağız içerisine yerleştirilen kompozit malzemelerin uzun periyotlarda vücut sıcaklığında kalacağı düşünüldüğünde daha tatminkâr tedavi süreçlerinin oluşmasına katkı sağlayacağı söylenebilir.

\section{Kaynaklar}

Brunthaler, A., Konig, F., Lucas, T., Sperr, W. and Schedle A., 2003. Longevity of direct resin composite restorations in posterior teeth. Clinical Oral Investigation, 7, 63-70.

Feuerstein, O., Zeichner, K., Imbari, C., Ormianer, Z., Samet, N. and Weiss, E.I., 2008. Temperature changes in dental implants following exposure to hot substances in an ex vivo model. Clinical Oral Implants Research, 19, 629-633.

Ghazal, M., and Kern, M., 2009. The Influence of Antagonistic Surface Roughness on the Wear of Human Enamel and Nanofilled Composite Resin Artificial Teeth. Journal of Prosthetic Dentistry, 101, 342-349.

Hahnel, S., Henrich, A., Burgers, R., Handel, G. and Rosentritt, M., 2010. Investigation of Mechanical Properties of Modern Dental Composites After Artificial Aging for One Year. Operative Dentistry, 35, 412-419.

Hahnel, S., Schultz, S., Trempler, C., Ach, B., Handel, G. and Rosentritt, M., 2011. Two-body wear of dental restorative materials. Journal of Mechanical Behaviour Biomedical Materials, 4, 237-244.

Heintze, S. D., 2006. How to qualify and validate wear simulation devices and methods. Dental Materials, 22, 712-734.

Jorgensen, K. D., 1980. Restorative Resins - Abrasion Vs Mechanical-Properties. Scandinavian Journal of Dental Research, 88, 557-68.

Koottathape, N., Takahashi, H., Iwasaki, N., Kanehira, M. and Finger, W.J., 2012. Twoand three-body wear of composite resins. Dental Materials, 28, 1261-1270.

Lazaridou, D., Belli, R., Petschelt, A. and Lohbauer, U., 2015. Are resin composites suitable replacements for amalgam? A study of twobody wear. Clinical Oral Investigation, 19, 1485-1492. 
Mair, L. H., Stolarski, T.A., Vowles, R.W. and Lloyd, C.H., 1996. Wear: Mechanisms, manifestations and measurement. Report of a workshop. Journal of Dentistry, 24, 141-148.

Musanje, L., and Darvell, B.W., 2004. Effects of strain rate and temperature on the mechanical properties of resin composites. Dental Materials, 20, 750-765.

Obrien, W. J., and Yee, J., 1980. Microstructure of Posterior Restorations of Composite Resin after Clinical Wear. Operative Dentistry, 5, 90-94.

Osiewicz, M. A., Werner, A., Pytko-Polonczyk, J., Roeters, F.J.M., and Kleverlaan C.J., 2015. Contact- and contact-free wear between various resin composites. Dental Materials, 31, 134-140.

Ramalho, A., Carvalho, M.D.B. and Antunes, P.V., 2013. Effects of temperature on mechanical and tribological properties of dental restorative composite materials. Tribology International, 63, 186-195.

Souza, J. C. M., Bentes, A.C., Reis, K., Gavinha, S. Buciumeanu, M., Henriques, B. Silva, F.S. and Comes, J.R. 2016. Abrasive and sliding wear of resin composites for dental restorations. Tribology International, 102, 154-160.

Van Dijken, J. W., 2000. Direct resin composite inlays/onlays: an 11 year follow-up. Journal of Dentistry, 28, 299-306.

Wimmer, T., Huffmann, A.M.S., Eichberger, M., Schmidlin, P.R. and Stawarczyk, B., 2016. Two-body wear rate of PEEK, CAD/CAM resin composite and PMMA: Effect of specimen geometries, antagonist materials and test set-up configuration. Dental Materials, 32, 127-136.

Yilmaz, E. C., and Sadeler, R., 2018. Investigation of Two- and Three-Body Wear Resistance on Flowable Bulk-Fill and Resin-Based Composites. Mechanics of Composite Materials, 54, 395-402.

Yilmaz, E., and Sadeler R., 2017. Yapay Ağız Sıvısında Termal Çevrimin Kompozit Restoratif Malzemelerinin Yüzey Pürüzlülüğü Üzerindeki Etkisi. Technological Applied Sciences, 12, 38-42. 